\title{
Mapping the value chain of imported shellfish in China
}

(C) <2019>. This manuscript version is made available under the CCBY-NC-ND 4.0 license http://creativecommons.org/licenses/by-nc$\underline{\mathrm{nd} / 4.0 /}$

\section{Citation}

Wang, O., Somogyi, S., \& Charlebois, S. (2019). Mapping the value chain of imported shellfish in China. Marine Policy, 99, 69-75.

https://doi.org/10.1016/j.marpol.2018.10.024

Author 1 Name: Dr. Ou Wang, corresponding author

E-mail address: ou.wang@waikato.ac.nz

Phone: +6478384758

Department: School of Accounting, Finance and Economics

Organization: University of Waikato

Mailing address: Private Bag 3105, Hamilton, New Zealand

Author 2 Name: Dr. Simon Somogyi

E-mail address: ssomogyi@uoguelph.ca

Phone: +1 5198244120

Department: School of Hospitality, Food \& Tourism Management

Organization: University of Guelph

Mailing address: 50 Stone Rd E, Guelph, ON, Canada

Author 3 Name: Dr. Sylvain Charlebois

E-mail address: sylvain.charlebois@dal.ca

Phone: +1 9024947822

Department: Faculty of Management

Organization: Dalhousie University

Mailing address: 6100 University Avenue, PO Box 15000, Halifax, NS, Canada

\section{Acknowledgement}

This study was funded by the Nova Scotia Department of Agriculture and supported by Dalhousie University. 


\section{Abstract}

3 This study explores the value chain structure and chain activities of the imported shellfish

4 industry in China. Data were collected from face-to-face semi-structured interviews in Guangzhou

$5(n=30)$ and Shanghai $(n=23)$ and a face-to-face survey in Shanghai $(n=71)$. Data analysis employed

6 both content and descriptive analyses. Results show that the value chain is composed of several

7 important members including foreign exporters, Chinese importers, wholesalers, resellers and

8 clearance companies. Business partnership is the main channel by which marketing information is

9 gained by chain members. Relationships are quite stable among the chain members, with quality,

10 price and credit items being the most important factors that influence chain relationships. It seems

11 that imported shellfish from some developed countries (e.g. Canadian and U.S. lobsters) have

12 reached a market saturation in China's first-tier cities (e.g. Guangzhou and Shanghai) and relevant

13 chain members face fierce competition. E-commerce is still not mature enough as a tool for the

14 marketing development of imported shellfish in China.

15

16 Keywords: imported shellfish; aquatic product; seafood; China; value chain; e-commerce.

17

18

19

20

21

22 


\section{Introduction}

The rapid economic growth of Asia, which is primarily due to large population size, is transforming the global food industry [1]. China is one of the more important emerging markets in Asia, and its growing middle-class consumer segment is resulting in an increase in demand for seafood [2-5]. The higher risk of microbial contamination in shellfish relative to non-shellfish aquatic products, a number of seafood safety incidents caused by coastal contamination, and a tradition of luxury seafood consumption have led to a tremendous growth in demand for imported high-value shellfish (i.e. Canadian and U.S. lobsters) [2-7]. The emerging demand for imported shellfish in China can help to diversify global shellfish export destinations from saturated developed countries to this huge and emerging market [4]. A need exists for global shellfish exporters and policy-makers to comprehensively understand the value chain structure for imported shellfish in China in order to develop effective and suitable marketing strategies and policies for this huge emerging market. However, there are different value chain structures for aquatic product industries between China and developed country markets (i.e. the USA) [8], and to our knowledge, there is no study that assesses the value chain structure and chain activities of the imported shellfish industry in China.

The concept of a value chain can be defined as a number of activities that firms operating in a specific industry perform in order to provide a product/service for the market [9]. Firms in value chains are vertically and horizontally networked, and exhibit shared perspectives and strategy, 2 mutual esteem, leadership, well-matched culture, teamwork, commitment, a "win-win" orientation, and positive attitudes to building a business system with aims at sustaining solid 4 relationships and providing value for final consumers [10,11]. A typical shellfish value chain often 45 includes members such as harvesters (fisherman), traders, importers, distributors, food service 
46

47

48

49 in the developed country chains) $[3,12]$.

50

51

52

53

54

55

56

57

62

\section{2. Data sources and research design}

64

65

67 68 cities in China. The information required for this study was obtained through face-to-face semi-

sectors and other players [12]. Chain structures may be different between domestic and imported shellfish value chains (e.g. no harvester for the imported chain) and between developed and developing shellfish value chains (e.g. with a stronger regulatory ability for resources and finance Value chain analysis focuses on recognizing chain activities (related to material flows, information flow and chain member relationships) in order to modify the chain structure and ensure the chain possesses the following characteristics: 1) Customers and consumers orientation; 2) Value creation, allocation, recognition and protection; 3) Obtaining right product each time; 4) Having effective and efficient logistics; 5) Having effective information and communications; 6) Shaping and sustaining effective relationships $[10,13,14]$. Although previous studies provide knowledge regarding the acquatic product industry in China, there are still no empirical studies that map the value chain and understand detailed chain activites for the imported shellfish industry in China - the largest fishery product market in the world $[3,4,5,15]$.

This study focuses on this unexplored area, namely the value chain mapping of imported shellfish in China. Face-to-face interviews and surveys are conducted with the chain members to map the value chain and chain activities for the imported shellfish industry in China.

An earlier expert panel (including Canadian stakeholders in shellfish export to the Chinese market in August and October of 2016) commented that first-tier cities (e.g. Beijing, Shanghai, Guangzhou and Shenzhen) had stronger consumption power for imported shellfish than lower67 tiered cities in China and should be a focus of study. As such, this study focused on the first-tier 
69

70

71 details).

72 Shanghai is an eastern city and an international metropolis of China, with a population of 23

73 million and an annual average personal income of \$USD 7864 [16]. Guangzhou is a southern

74 Chinese city and the provincial capital of Guangdong province, with a population of 14.04 million

75 and an annual average personal income of SUSD 7376 in 2016 [16]. Traditionally, local dishes

76 often contain seafood in these two cities, e.g. fresh-water crab in Shanghai and a variety of seafood

77 in Guangzhou [17].

78

79 > >>> Insert Table 1

80

81

Regarding the face-to-face semi-structured interview, a discussion guide was developed to

82 understand interviewees' daily business activities and requirements related to imported shellfish

83 (e.g. species, country of origin, e-commerce, suppliers and buyers). The interviews were audio- or

84 text-recorded in Chinese. An interview transcript was created from 165 minutes of audio-

85 recordings and 24 text-notes (for those interviewees who refused audio recording). These files

86 were coded into an Excel file (in English) and content analysis was performed on the data.

87 Based on the qualitative research findings from the semi-structured interview and from

88 previous literature $[10,18]$, a questionnaire was developed for the face-to-face survey in Shanghai

89 to quantitatively understand interviewees' chain activities related to material flows, information

90 and communication flows, and relationships with other chain members. Each survey took 10 to 20

91 minutes. Descriptive analyses (e.g. mean value and percentage) were employed for data analysis. 


\section{3. Results and discussion}

\subsection{Value Chain map and material flow}

94 Figure 1 shows the value chain map of imported shellfish in China based on the findings of 95 the face-to-face semi-structured interviews. There are many organizations involved in the value 96 chain, including foreign exporters, Chinese importers, wholesalers, resellers and clearance 97 companies. While this study did not collect data from upstream foreign chain members (e.g.

98 harvesters or exporters) and final consumers. However, information on those chain members can 99 be obtained from previous studies $[2,4,5,10,12]$.

$101>>>>>$ Insert Figure 1 exporters. Regarding fresh-frozen and frozen shellfish, the species and their original countries have 105 to appear on a list edited by the Chinese government; otherwise, the shellfish products cannot be 106 legally imported. Foreign exporters have to be registered in China to export aquatic products. 107 Foreign exporters have to provide proof of place of origin for wild shellfish, and farmed shellfish 108 has to pass food safety standards. For example, refrigeration, and hygiene conditions in foreign 109 exporters' warehouses have to reach the standards required by the Chinese government. Further, 110 Chinese importers have to apply for a license and quarantine permit from the local Commodity 111 Inspection and Testing Bureau (in Guangzhou and Shanghai). Regarding live shellfish, the license 112 includes an annual quota amount for the Chinese importer. When a Chinese importer doesn't use 113 their quota in one year, it is difficult for that importer to obtain a new quota in the following year. 114 Live shellfish are transported to these two cities by air with ice. A small amount of frozen or fresh- 
115 frozen shellfish is also delivered to the two cities by air, while the majority is transported to China 116 by boat (with cold chain transport).

117 Clearance companies provide services to assist imported shellfish into China such as: 1)

118 faster customs clearances; 2) introducing qualified logistic companies to Chinese importers, and/or

119 arranging the transportation of imported shellfish inside China to locations required by the Chinese

120 importers; 3) helping Chinese importers and foreign exporters (who have no qualification, import

121 quota and are not registered by the Chinese government) to borrow certification and an import

122 quota from other Chinese importers and foreign exporters. Further, some clearance companies

123 directly import shellfish, so they also play a role as Chinese importers.

124 Chinese importers sell most of their shellfish to wholesalers in aquatic/seafood markets.

125 Shellfish are delivered to the aquatic markets or are picked up by the wholesalers at airports or

126 harbors. The two cities both have large aquatic markets, such as the Huang Sha market in

127 Guangzhou and the Jiang Yang market in Shanghai, where wholesalers are the main suppliers of

128 shellfish to local restaurants and other retailers. Some importers also have shops in the aquatic

129 markets of the two cities and play roles as both importers and wholesalers. China has more than

13030 large aquatic markets located in large and/or coastal cities. These aquatic markets handle the

131 bulk of imported shellfish and are the most important suppliers for shellfish consumption both in

132 those cities and surrounding cities. Therefore, foreign shellfish exporters and marketers should try

133 to better understand these aquatic markets in order to find potential markets and diversify their

134 export destinations in China.

135 Wholesalers or importers in the aquatic markets sell most of their shellfish products to local

136 restaurants. Some of them sell a small amount of shellfish (with lower quality compared to those

137 sent to restaurants) directly to consumers who visit the markets. Furthermore, they also sell their 
138 shellfish to resellers, especially for frozen products. There are two kinds of resellers: local resellers

139 and resellers from other cities around Shanghai and Guangzhou. The local resellers have good

140 networks with local restaurants and often have their own cold stores and tend to purchase a large

141 amount of frozen shellfish from the wholesalers and importers. The resellers from other cities

142 purchase shellfish from wholesalers and importers in Shanghai and Guangzhou and sell the

143 shellfish to the local markets in their own cities (e.g. Hangzhou and Wuxi cities around Shanghai,

144 and Dongguan and Foshan cities around Guangzhou).

145 The findings from the face-to-face survey confirm this chain structure (by multiple choice

146 questions that aim to recognize the business types of participants' downstream and upstream

147 partners). Participants mainly purchase their imported shellfish from importers or foreign exporters

148 (77.5\% of the total sample). They also purchase imported shellfish from the wholesalers located

149 in their domestic aquatic markets ( $54.9 \%$ of the total sample). A small share of them $(8.5 \%$ of the

150 total sample) purchase imported shellfish from clearance companies.

151 Most of participants in the survey (above $70 \%$ of the total sample) sell imported shellfish to

152 the local food service industry (e.g. hotels and restaurants) and the wholesalers located in their

153 aquatic markets. They also sell imported shellfish to resellers (local and from other regions),

154 consumers and retailers. On average, participants indicate that above $70 \%$ of their imported

155 shellfish is sold to the food service industry by themselves and their downstream partners (e.g.

156 resellers). This is in line with the previous findings that Chinese consumers mainly consume

157 shellfish in food service sectors, rather than their homes, as they consider shellfish dishes as a

158 premium choice when establishing networks with important people and to elevate their face159 consciousness $[2,4,5]$. 
161

162

163

164

165

166

167

168

169

170

171

172

173

174

175

176

177

178

179

180

182

181 lobsters are more popular than North American 'Boston' lobster in Guangzhou, because local

\subsection{Price and profit}

The price of live shellfish, especially high-value shellfish such as lobster and king crab, fluctuates rapidly. Frozen shellfish generally has a transparent price, and the price can be easily obtained through China's online Business to Business (B2B) platforms.

Chinese importers and restaurants have a high profit margin on imported shellfish, while wholesalers generally have a low profit margin for that product. Wholesalers often use a strategy of large sale and low price for frozen shellfish, and make small profits but with a quick turnover. The prices of frozen shellfish from wholesalers are also forced down by local resellers who have large frozen storage facilities and long-term relationships with local restaurants and subsequently control the direct channels of shellfish supplies for restaurants.

\subsection{Physical requirements of shellfish}

Restaurant managers and wholesalers discuss that freshness and good-meat-texture are the major reasons for them to purchase shellfish products. Furthermore, some restaurant managers mention that good value for money is an important factor for their shellfish purchase, as their current businesses are not as prosperous as in previous years. The purchase of some shellfish species also depends on the production season. For example, oyster can only be on the menus of restaurants for one or two months when it is in season. In general, interviewees agree that the most important influencing factor for their shellfish selection is consumer preference. Consumers have different preferences in different regions. For example, Australian, Vietnamese and Indonesian 82 consumers dislike the meat texture of Boston lobster. Also, when sitting around a table for dinner 
183 or lunch as a group in Shanghai, consumers require a larger lobster ( $750 \mathrm{~g}$ to $1250 \mathrm{~g})$ to share, while 184 those in Zhejiang province need smaller lobsters (400g to 600g) for each person.

1863.4 Peak season and timing for supply

187 Restaurant managers and wholesalers agree that the peak seasons of shellfish consumption 188 are during Chinese festivals (especially during Chinese New Year). They also consider summer as 189 a peak season for shellfish consumption in China with at least double the number of sales than 190 during other seasons.

191 The timing of supply required by restaurants is from 'per day' to 'per weeks', depending on 192 different shellfish species, consumption volume and production form. Restaurants often require a 193 supply timing of 'per day' for live shellfish such as lobster and king crab in order to guarantee the 194 freshness of shellfish in restaurant dishes. They require a supply timing of 'per week' for frozen 195 shellfish, because they often have freezer storage facilities to keep them in. The wholesalers in 196 Huangsha market and Jiangyang market businesses are open 24 hours per day and they will receive 197 live shellfish from the airport at any time of the day if it is arriving from Chinese importers. Some 198 large Chinese importers also deliver their shellfish, such as Vietnamese shrimp, to wholesalers in 199 the markets on a daily basis.

200

2013.5 Countries-of-origin of imported shellfish

202 The face-to-face semi-structured interviews recognize that countries around the world are 203 selling their shellfish and competing with domestic shellfish (e.g. farmed scallop from Dalian city) 204 in the Chinese market. As such, global shellfish exporters face stiff competition in this huge 205 market. 
Figure 2 shows the results of a multiple-choice question from the Shanghai face-to-face 207 survey that aims to understand country of origin (COO) of imported shellfish in participants' 208 businesses. Half of the total participants sell Canadian shellfish, meanwhile over $40 \%$ of the 209 participants sell U.S. shellfish, while a significantly lower percentage of the participants report 210 business dealings with other COOs for shellfish (under $26 \%$ of the total participants). It seems that 211 North American shellfish products have had a much better market penetration than shellfish 212 products with other COOs in Shanghai. Some participants mention that U.S. and Canadian 213 shellfish products, lobster in particular, are more popular in Shanghai and its neighboring cities 214 than other Chinese regions (e.g. Guangzhou).

215 In addition, around $60 \%$ of the total participants indicate that they prefer to purchase shellfish 216 from both developed and developing countries. Some of the participants also mention that there is 217 a smaller profit margin for shellfish from developed countries (e.g. Canada and the U.S.) than that 218 from developing countries (e.g. India and Vietnam) due to the more mature and saturated market 219 for developed country shellfish than that for developing country shellfish.

220

$221>>>>>$ Insert Figure 2

222

2233.6 Imported shellfish species

224 The face-to-face semi-structured interviews reveal that a great deal of imported shellfish 225 species appear in the markets of Shanghai and Guangzhou, including lobster, king crab, shrimp, 226 sea crab, snow crab, scallop, mussels, clam, oyster and so on. These imported shellfish species 227 have to compete with local shellfish species (e.g. fresh water crab, mantis shrimp, oyster, scallop 228 and sea crab) for market shares in China. 
Figure 3 displays the results of a multiple-choice question from the Shanghai face-to-face

230 survey that aims to understand which imported shellfish species comprise the participants'

231 businesses. Lobster and shrimp/prawn are most common shellfish species in the business. This

232 corresponds with the previous findings that Chinese consumers have stronger positive attitudes

233 toward lobster and shrimp/prawn than that for other shellfish species [4]. As such, there are more

234 wholesalers and importers that want to seize this huge potential market demand for lobster and

235 shrimp/prawn in China in comparison with that for other imported shellfish species.

236

$237>>>>>$ Insert Figure 3

2393.7 Information and communication flows

240 Figure 4 highlights the results of a multiple-choice question from the face-to-face survey that

241 aims to understand the channels often used by participants in order to obtain marketing information

242 including demand, availability, price and customers' requirements in terms of product attributes

243 and service levels. Business partners dominate the information and communication channels; they

244 are chosen as main channel to gain marketing information from over $90 \%$ of participants.

245 Furthermore, about $18 \%$ of the total sample report gaining marketing information through social

246 networks and the Internet. None of the other channels were selected by over $6 \%$ of participants. In

247 addition, around $45 \%$ of the interviewees report that they can always obtain enough marketing

248 information regarding imported shellfish, while the other participants indicate that they are not

249 sure, or that they cannot gain enough marketing information.

250 Therefore, methods should be improved for Chinese shellfish importers/wholesalers to

251 obtain marketing information in order to let them have an exact and timely understanding of 
252 marketing situations for the imported shellfish products they are doing business with. To fulfill

253 this purpose, some efforts can be recommended i.e. foreign shellfish exporters and policy-makers

254 could use Chinese Internet and social networks (e.g. WeChat) to provide more marketing

255 information to shellfish import chain members (e.g. importers and wholesalers) in China.

256

257 >>>> Insert Figure 4

258

2593.8 Relationships among chain members

260 Regarding the face-to-face survey, participants on average have collaborated with their most

261 important suppliers for 7 years and with their most important customers for 6 years. Around $60 \%$

262 of the participants do not sign business contracts with their suppliers and customers. Over $50 \%$ of

263 the participants indicate that they always make business with the same customers and/or suppliers.

264 Furthermore, $77 \%$ of the participants admit that their businesses are very familiar to their

265 customers and $66 \%$ of them also admit this for their suppliers. In addition, over $90 \%$ of the

266 participants indicate that they do not often have hygiene or safety problems with their customers

267 and suppliers. They mention that there are rigorous checks and tests by China's customhouse and

268 aquatic market governance so that imported shellfish with safety or hygiene problems are not

269 allowed to enter China or aquatic markets in Shanghai. Over $70 \%$ of participants report to have no

270 problem regarding other issues with their customers and suppliers. Therefore, it seems that

271 relationships among chain members are quite stable as they make business dealings with the same

272 suppliers and customers over a long period of time and deeply understand each other's businesses.

273

274 Figure 5 shows the results of two multiple-choice questions from the face-to-face survey, 275 used to understand important factors influencing participants' relationships with their main 
276 suppliers and customers. Quality, price and credit items (e.g. on time delivery or payment) are

277 recognized as the most important influencing factors for both the suppliers and customers.

278 Therefore, foreign shellfish exporters and policy-makers might improve their relationships with

279 Chinese importers and wholesalers through making relevant marketing promotions and policies

280 related to these important marketing factors i.e. price (e.g. reasonable and acceptable), credit items

281 (e.g. transportation on time) and quality (e.g. a low mortality rate or a high level of freshness).

282 In particular, quality-related promotions and policies, such as creating quality standards for

283 shellfish based on Chinese market demand, should take precedence. This is the case as the majority

284 of quality-assurance activities, such as adhering to strict standards for purchasing, storing and

285 cooking shellfish to ensure the highest quality of shellfish dishes for consumers, are shouldered by

286 value chain members rather than final consumers in China [4]. Freshness is the most important

287 quality attribute for shellfish as perceived by Chinese people due to its important role in enhancing

288 the favored umami taste for shellfish dishes $[4,5]$. As such, foreign shellfish exporters and

289 marketers should develop marketing strategies and policies that ensure a high level of freshness

290 for their shellfish products delivered to the Chinese market. Furthermore, mood-enhancement,

291 such as making consumers have a good mood or a feeling of relaxation, and ethics-friendly, such

292 as environmental friendly or supportive of sustainability, are two other quality attributes for

293 shellfish as perceived by Chinese people due to their needs for face-consciousness and gradually

294 increased ethical concerns toward shellfish production $[4,5]$. In that perspective, relevant

295 marketing promotions and policies are recommended i.e. selecting suitable shellfish products to

296 meet face-consciousness needs and developing eco-friendly labels applied to the Chinese market. 297

298 >>>>> Insert Figure 5 


\subsection{Competition and future prospects}

301 Regarding the face-to-face interviews, around 55\% of the total participants indicate that they

302 feel motivated by the future prospects for their businesses as part of the imported shellfish industry,

303 while the rest of the participants are not sure or do not feel motivated in this regard. Besides, over

$30470 \%$ of the total participants indicate that they face fierce competition in the imported shellfish

305 business. It seems that participants are not fully confident in the future of the imported shellfish

306 industry due to the fierce competition.

307 This is in line with the qualitative findings of the face-to-face semi-structured interview.

308 Some restaurant-managers and wholesalers indicate worse business conditions compared to

309 previous years due to the Chinese government policy towards anti-corruption. It is harder to find

310 people who eat luxury shellfish than before and therefore they require shellfish products with

311 higher value for money. Furthermore, some wholesalers in the interview also indicate the serious

312 market saturation for some imported shellfish species in Shanghai and Guangzhou i.e. Australian,

313 Canadian and Boston lobsters, snow crab and Dungeness crab in the market.

314 Therefore, it might not be a wise choice for foreign exporters and policy-makers to continually work on enlarging market shares for their shellfish species and products with serious

316 market saturation in first-tier cities (e.g. Shanghai and Guangzhou). Instead, they might seek to 317 expend the market share of these shellfish species and products in other tiered cities (e.g. second318 and third-tier cities) to diversify their export destinations for potential profit growth in China. 319 Furthermore, foreign exporters and policy-makers should develop and promote shellfish species 320 and products that meet the new market demand in China i.e. good value for money. 


\subsection{E-commerce for imported shellfish}

324 There has been a dramatic increase in e-commerce for aquatic products in China recently [4,

325 5]. However, the findings from this study indicate that e-commerce has still a long way to go for

326 imported shellfish in China. Participants in the face-to-face survey report a small share (less than

$32710 \%$ ) of e-commerce (B2B and B2C) in their current imported shellfish business, although they

328 expect to enlarge the share to $40 \%$ in the future if the e-commerce environment changes and

329 provides better conditions for imported shellfish. Currently, they face a number of problems in this

330 regard, such as high mortality when shellfish reaches consumers' homes and the credit issues in

331 the volume and quality of shellfish purchased from B2B platforms. Meanwhile some restaurant

332 managers in the face-to-face semi-structured interview mention that there is a risk in directly

333 purchasing live shellfish from online B2B platforms as they cannot know the quality of the boxed

334 shellfish before delivery, which is different from buying live shellfish from the tanks of

335 wholesalers in aquatic markets as they can clearly see the condition of live shellfish. These findings

336 are line with the fact that online shopping is not a favorite choice for aquatic products by consumers

337 with a small market share (less than $5 \%$ ) for aquatic product consumption in China $[2,4]$.

338 Therefore, foreign exporters and policy-makers should not put a great deal of emphasis on

$339 \mathrm{~B} 2 \mathrm{~B}$ and $\mathrm{B} 2 \mathrm{C}$ platforms for their shellfish products in China, though that may become a better

340 choice in the future when the e-commerce environment is mature enough for shellfish business.

341 Instead, O2O (online to offline) might be a more suitable e-commerce type for imported shellfish

342 in the current Chinese market, where consumers order and make payment online and physically

343 consume shellfish products offline, i.e. the Fresh Hema Stores recently opened by the Chinese e-

344 commerce giant, Alibaba [19]. 


\subsection{Limitations}

This study does have some limitations. Firstly, it does not focus on a whole-of-chain

348 perspective as data was not collected from upstream foreign chain members (e.g. harvesters or

349 exporters) and final consumers. However, information related to consumer behavior and upstream

350 chain activities in shellfish industry can be obtained from previous studies $[2,4,5,10,12]$.

351 Secondly, the design of the face-to-face survey was developed from a previous study [18]. This

352 may be a methodological limitation. However, the survey design was used as it allowed us to

353 rapidly recognize chain members' activities related to material flows, information and

354 communication flows, and relationships with other chain members. Thirdly, this study only

355 focused on product attributes related to Chinese consumers' quality perceptions for shellfish, for

356 example freshness, ethics-friendly and mood-enhancement, as quality was the most important

357 influencing factor for value chain members' relationships with both suppliers and customers.

358 Regarding other important product attributes that drive Chinese consumers' choice behaviors for

359 shellfish, please refer to previous consumer studies $[2,4,5]$. It is recommended that future studies

360 focus on the fields of shellfish consumer behavior in China, such as understanding different

361 consumer segments' decisions for imported shellfish consumption in China, as providing or

362 creating values for final consumers is an important task for chain members in a value chain [10, $36311]$.

365 4. Conclusion

367 - the largest aquatic product market in the world. This presents a great opportunity for global 
368 shellfish exporters and policy-marketers to diversify global shellfish export destinations from

369 saturated markets in developed countries to a huge and emerging market. By using face-to-face

370 interviews and surveys, this is the first empirical study to explore the value chain structure and

371 chain activities of the imported shellfish industry in China. The value chain is composed of several

372 important members including foreign exporters, Chinese importers, wholesalers, resellers and

373 clearance companies. Business partners are the main channels through which chain members gain

374 marketing information. Relationships are quite stable among the chain members, with quality,

375 price and credit items being the most important factors that influence chain relationships. It seems

376 that imported shellfish from some developed countries (e.g. Canadian and U.S. lobsters) have

377 reached market saturation in China's first-tier cities (e.g. Guangzhou and Shanghai) and relevant

378 chain members face fierce competition. E-commerce is still not mature enough as a tool for the

379 marketing development. The first-hand findings in this study provide valuable inputs for global

380 shellfish exporters and policy-makers to better understand the value chain and its chain activities

381 for imported shellfish in China in order to develop effective marketing strategies and policies for

382 their shellfish products in this huge emerging market.

\section{Acknowledgement}

385 This study was funded by the Nova Scotia Department of Agriculture and supported by 386 Dalhousie University.

\section{References}

389 [1] V. P. Gandhi, Z. Zhou, Food demand and the food security challenge with rapid economic growth in the emerging economies of India and China. Food Res Int 2014; 63: 108-124. 
391 [2] M. Fabinyi, N. Liu, Q. Song, R. Li, Aquatic product consumption patterns and perceptions 392 among the Chinese middle class. Region Stud Mar Sci 2016; 7: 1-9.

393 [3] M. Fabinyi, Producing for Chinese luxury seafood value chains: Different outcomes for 394 producers in the Philippines and North America. Mar Policy 2016; 63:184-190.

395 [4] O. Wang, S. Somogyi, Chinese consumers and shellfish: Associations between perception, 396 quality, attitude and consumption. Food Qual Prefer 2018; 66: 52-63.

397 [5] O. Wang, S. Somogyi, R. Ablett, General image, perceptions and consumer segments of 398 luxury seafood in China: a case study for lobster. Br Food J 2018; 120 (5).

399 [6] C. Lin, Z. S. Liu, C. Y. Tan, Y. P. Guo, L. Li, H. L. Ren, Y. Zhou, Contamination of 400 401 402 403 404 405 406 407 408

409 [10] M. Gooch, A. Felfel, Characterizing the ideal model of value chain management and 410 barriers to its implementation. Guelph: George Morris Center; 2008.

413 commercially available seafood by key diarrhetic shellfish poisons along the coast of China. Environ Sci Pollut R 2015; 22: 1545-1553.

[7] P. Xu, Y. Zeng, Q. Fong, T. Lone, Y. Liu, Chinese consumers' willingness to pay for greenand eco-labeled seafood. Food Control 2012; 28: 74-82.

[8] M. Fabinyi, M. Pido, B. Harani, J. Caceres, A. Uyami - Bitara, A. De las Alas, E. M. Ponce de Leon, Luxury seafood consumption in China and the intensification of coastal livelihoods in Southeast Asia: the live reef fish for food trade in Balabac, Philippines. Asia Pacific Viewpoint 2012; 53(2): 118-132.

[9] L. E. Porter, Competitive Advantage. New York: The Free Press; 1985. 40 (20) 2008.

[11] C. Lin, Z. S. Liu, C. Y. Tan, Y. P. Guo, L. Li, H. L. Ren, Y. Zhou, Contamination of commercially available seafood by key diarrhetic shellfish poisons along the coast of China. Environ Sci Pollut Res 2015; 22(2): 1545-1553. 
414 [12] G. Thériault, J. Hanlon, L. Creed, Report of the Maritime Lobster Panel. Prince Edward 415 Island: Prince Edward Island Department of Fisheries, Aquaculture and Rural 416 Development; 2013.

417 [13] J.P. Womack, D.T. Jones, Lean Solutions. New York: Free Press; 2005.

418 [14] R. Collins, T. Dunne, M. O'Keeffe, The locus of value: a hallmark of chains that 419 learn. Supply Chain Management 2002; 7(5): 18-21.

420 [15] K. B. Lindkvist, T. Trondsen, J. Xie, Restructuring the Chinese seafood industry, global $421 \quad$ challenges and policy implications. Mar Policy 2008; 32(3): 432-441.

422 [16] National Bureau of Statistics of the People's Republic of China, China stastistical yearbook 423 2016. Beijing: China Statistics Press; 2017.

424 [17] Zhao, R. G. Chinese dietary culture overview (Vol. 6). Beijing: Higher Education Press; 4252003.

426 [18] R. C. Collins, B. Dent, L. B. Bonney, A guide to value-chain analysis and development for 427 overseas development assistance projects. Canberra: Australian Centre for International $428 \quad$ Agricultural Research; 2016.

429 [19] A. Najberg, Hema supermarket offers shoppers a 'new retail' experience.

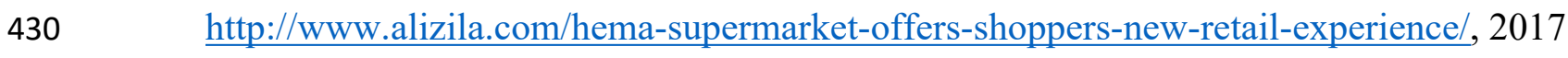
$431 \quad$ (accessed 20 March 2018).

432 


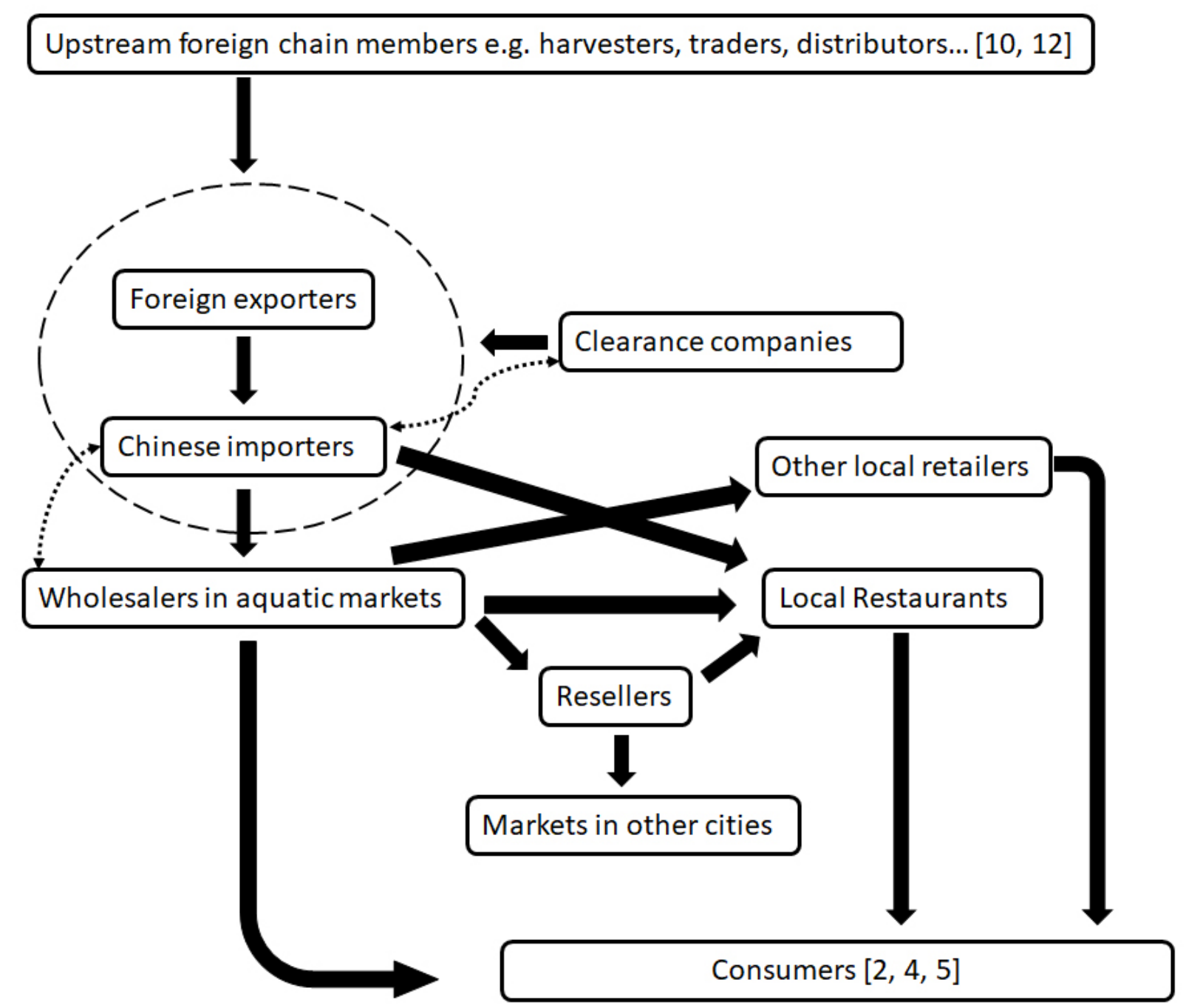

1

2 Fig. 1.

3

4

5 


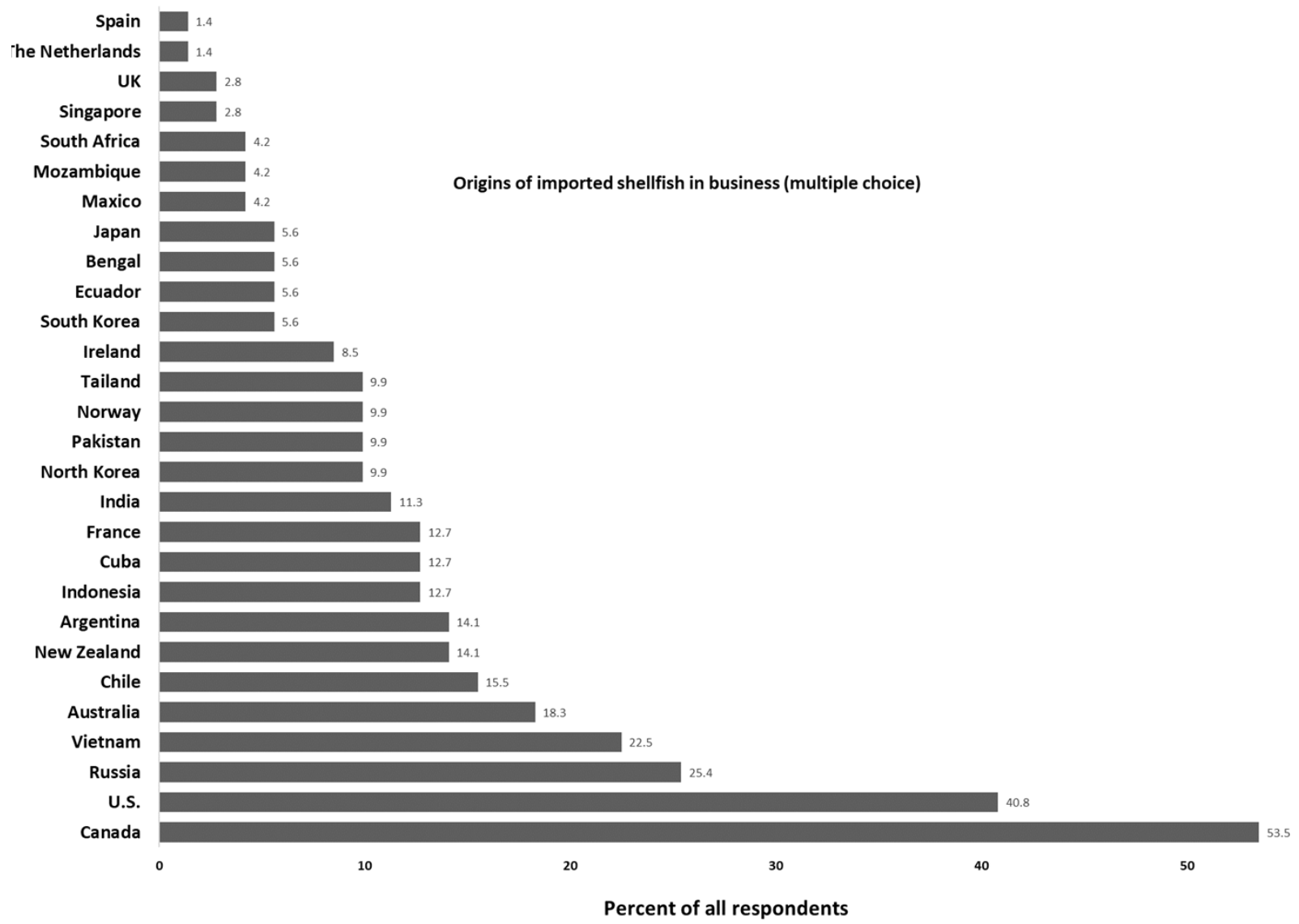

8 Fig. 2.

9

10

11 


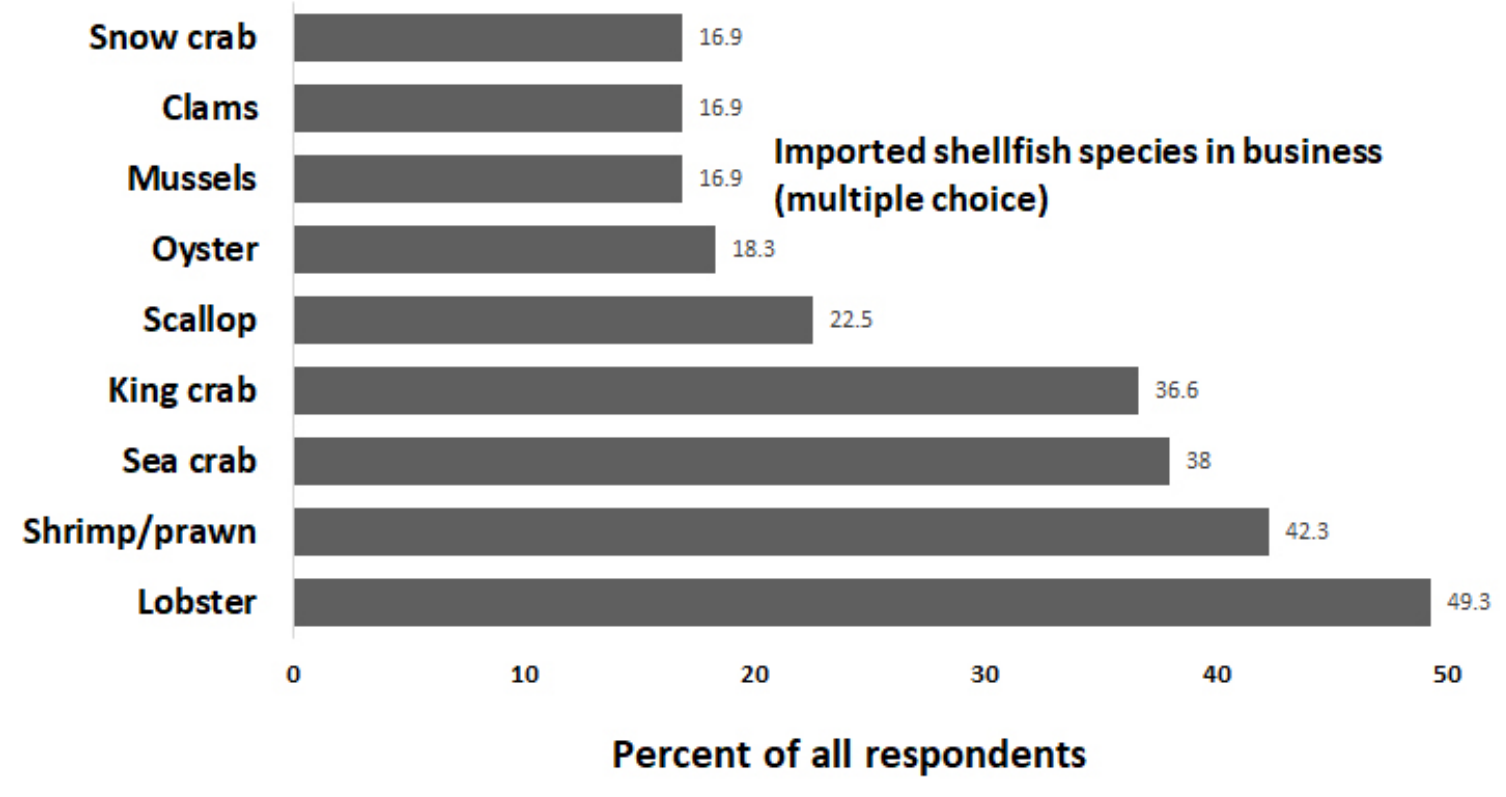

13 Fig. 3

14 


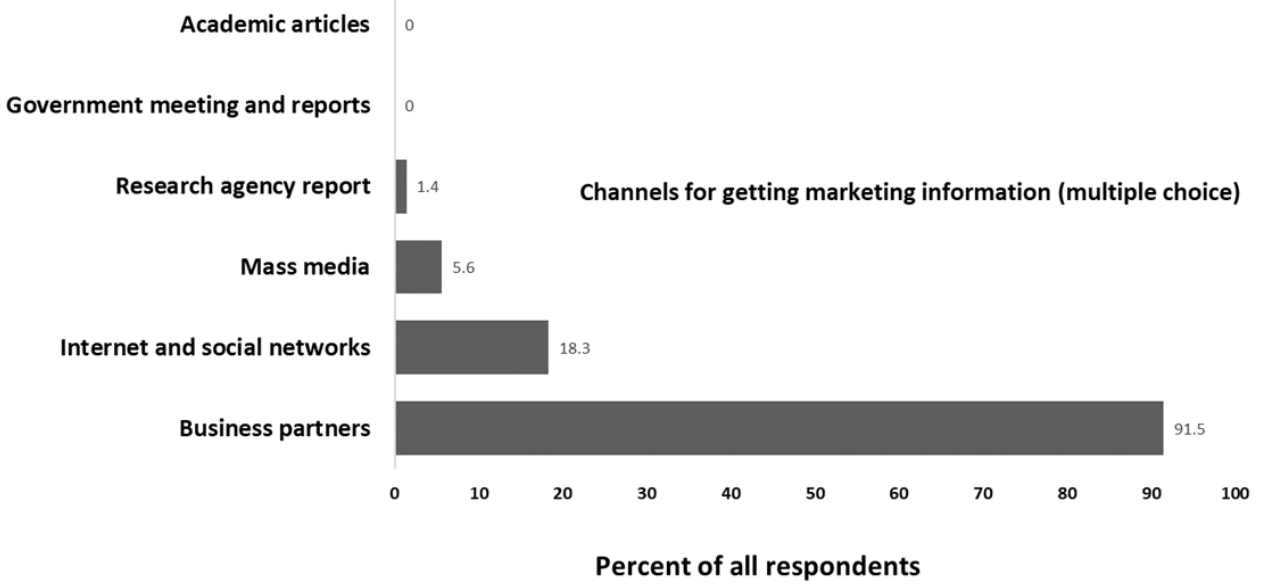

25 Fig. 4.

26

27

28

29

30

31

32

33

34

35

36

37

38

39

40

41

42

43 

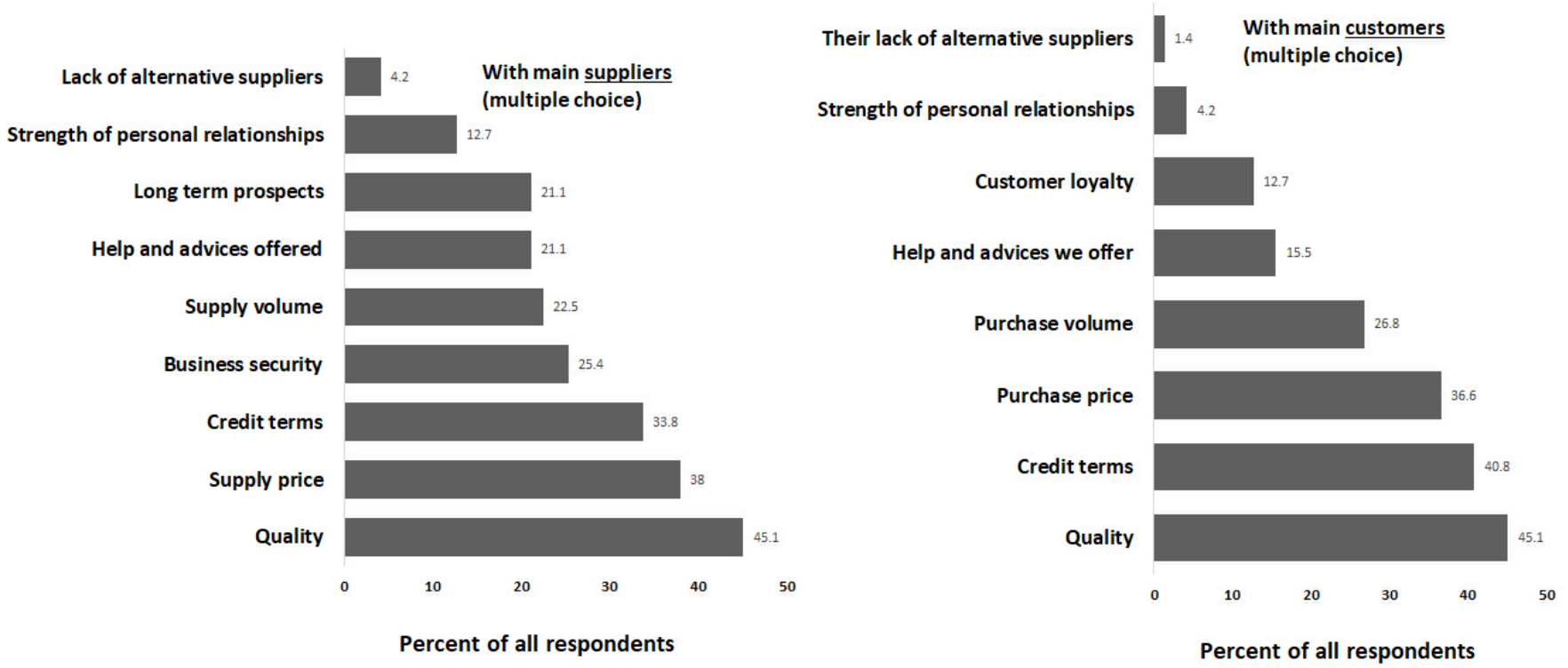

Percent of all respondents

45 Fig. 5.

46

47 
2 Fig. 1. Value chain map of imported shellfish in China

3

4 Fig. 2. Country of origins for imported shellfish in participants' businesses in the face-to-face survey 5

6 Fig. 3 Imported shellfish species in participants' businesses in the face-to-face survey 7

8 Fig. 4. Channels for gaining marketing information in participants' businesses in the face-to-face 9 Survey

10

11

12

13

14

15 


\section{Table 1}

Sample details of the face-to-face interview and survey

\begin{tabular}{lcc}
\hline & Face-to-face semi-structured interview \\
\hline Business type & Guangzhou $(\mathrm{n}=30)$ & Shanghai $(\mathrm{n}=23)$ \\
\hline Restaurant & 8 & 9 \\
Wholesaler & 19 & 12 \\
Clearance company & 3 & 2 \\
\hline \multicolumn{2}{l}{ Business type } & Face-to-face survey \\
\hline Both wholesaler and importer & Shanghai $(\mathrm{n}=71)$ \\
Only wholesaler & 26 \\
Only importer & 37 \\
\hline
\end{tabular}

